\title{
Evaluating the esophageal epithelial integrity: more complex than it seems.
}

Ricard Farré ${ }^{1,2}$

(1) Translational Research Center for Gastrointestinal Disorders, KU Leuven, Leuven, Belgium.

(2) Centro de Investigación Biomédica en Red de Enfermedades Hepáticas y Digestivas, (Ciberehd), Instituto de Salud Carlos III, Spain.

I read with great interest the study performed by van Rhijn BD et al. "Histological Response to Fluticasone Propionate in Patients With Eosinophilic Esophagitis Is Associated With Improved Functional Esophageal Mucosal Integrity" (6). The rise in the prevalence of eosinophilic esophagitis (EoE) is potentiating the basic research on the pathophysiology of this disease as is shown by the increasing amount of publications during the last 5 years. More recently, the impaired epithelial integrity present in these patients has also been suggested as a key player in EoE.

Authors of the present study suggest that Fluticasone Propionate treatment decreases eosinophilic inflammation and improves the esophageal mucosal barrier integrity in adult EoE patients. Epithelial integrity was measured in vivo, but also in vitro with the gold standard Ussing chamber technique.

Several relevant concerns regarding in vitro measurements rose after reading the present study. 1- It is very difficult to believe that authors were able to properly mount and study all the taken biopsies in an adaptor with an opening of $2 \mathrm{~mm}$ diameter, even using a high capacity Jumbo forceps.

2- Compared with data using the same equipment and size of the adaptor from the very experienced and pioneer group of Prof. Roy Orlando, the transepithelial electrical resistance (TEER) values currently reported in patients, but also from healthy volunteers, are extremely low: at least half the magnitude (2-4). Recently, Sherrill et al. published that EoE patients with active disease have a TEER of $80 \Omega \mathrm{xcm}^{2}(\mathrm{~N}=9)$. The healthy volunteer population in this study has

a TEER of $210 \Omega x \mathrm{~cm}^{2}(\mathrm{~N}=6)$. The same group reported even values of more than $300 \Omega \times \mathrm{cm}^{2}$ in two larger population of healthy volunteers $(N=13$ and $N=25)(2 ; 4)$. TEER values of the present study are $34 \Omega x \mathrm{xm}^{2}(\mathrm{~N}=10)$ and $116 \Omega \times \mathrm{xm}^{2}(\mathrm{~N}=11)$ for patients and the control group respectively. 
3- Even more striking is that the flux of fluorescein in the luminal to basolateral direction is extremely high, not only in patients with EoE but also in healthy volunteers, showing that the biopsies are not properly placed and completely covering the opening of the adaptor. The flux (J) of a probe is calculated by $J=\left(\Delta c \times V_{c h}\right) /(\Delta t \times A)$ and is expressed as $\mathrm{nmol} / \mathrm{h} / \mathrm{cm}^{2} . \Delta c$ is the concentration difference of the probe in the acceptor chamber at time $t_{1}$ and $t_{2}, \Delta t$ is the time difference $t_{1}-t_{2}, V_{c h}$ is the volume of the hemi-chamber and $A$ is the area of the specimen. Due to the concentration dependence, fluxes from different studies cannot be compared when the concentration of the probe in the donor chamber is different. To make this possible the apparent permeability $\left(P_{a p p}\right)$ is used and it origins from the division of the flux $J$ by the concentration of the probe in the donor chamber, the unit is $\mathrm{cm} / \mathrm{s}$. The $P_{a p p}$ for the healthy control group of the present study, taking and average flux of $500 \mathrm{nmol} / \mathrm{h} / \mathrm{cm}^{2}$, is $105.2 \times 10^{-6} \mathrm{~cm} / \mathrm{s}$. This is much higher than the values calculated from the control group of the study by Jovov et al (2). In this study authors found that the concentration of fluorescein in the basolateral side was in that group $0.01 \%$ of the concentration added at the luminal side ( $1 \mathrm{mM}$ or $0.37 \mathrm{mg} / \mathrm{mL}$ ), based on the formulas explained before the $J$ is $8 \mathrm{nmol} / \mathrm{h} / \mathrm{cm}^{2}$ and the $P_{a p p}$ is $2.2 \times 10^{-6} \mathrm{~cm} / \mathrm{s}$. In another study by Bjorkman et al., authors directly reported that the $P_{a p p}$ of the esophageal epithelium is $0.2 \times 10^{-6} \mathrm{~cm} / \mathrm{s}(1)$ by using an $A$ of $0.29 \mathrm{~cm}^{2}$. By using an adaptor with an $A$ of $0.017 \mathrm{~cm}^{2}$, we found in one of our cohorts of healthy volunteers $(\mathrm{N}=12)$ that average TEER after $1 \mathrm{~h}$ was around $250 \Omega \times \mathrm{cm}^{2}$, the $J$ was $1 \mathrm{nmol} / \mathrm{h} / \mathrm{cm}^{2}$ and the $P_{\text {app }}$ was $0.1 \times 10^{-6} \mathrm{~cm} / \mathrm{s}$ (unpublished data). It is very remarkable that the $P_{a p p}$ for fluorescein reported in the present study in healthy volunteers is very high and never achieved in a simple epithelium from other segments of the gastrointestinal tract $(1 ; 5)$. Moreover, it is hard to believe that an increase of $30 \Omega \times \mathrm{cm}^{2}$ after fluticasone treatment is able to normalize the flux of fluorescein, as is shown by the similar values observed in the historic cohort $\left(693 \mathrm{nmol} / \mathrm{h} / \mathrm{cm}^{2}(0-2,589)\right.$ vs. $345 \mathrm{nmol} / \mathrm{h} / \mathrm{cm}^{2}(0-1451)$, $p=0.53$ ) . TEER after treatment in EoE patients still is half, when compared with the historic cohort (116 $\Omega \times \mathrm{xm}^{2}$ vs. $\left.64 \Omega \times \mathrm{cm}^{2}\right)$.

Based on these arguments, I am confident to state that the biopsies assessed in the present study are not well placed in the adaptor, as shown by the extremely high $P_{a p p}$ and the low TEER. Unfortunately, authors do not mention which criteria they use to assure that biopsies are viable and well mounted. This makes the interpretation of the results very difficult. They might see a significant difference in their results, however, badly mounted biopsies cannot be used to make scientifically correct conclusions. Experienced researchers in this type of measurements know all very well that not all the biopsies initially studied can be included. 
I would like to conclude saying that I strongly encourage the authors of the present study and eventually researchers of other research groups to assure correct measurements of epithelial integrity with the golden Standard Ussing chambers technique, when using endoscopic biopsies independently from the segment of the gastrointestinal tract or other tissues.

\section{Reference List}

1. Bjorkman E, Casselbrant A, Lundberg $\mathbf{S}$ and Fandriks $\mathrm{L}$. In vitro assessment of epithelial electrical resistance in human esophageal and jejunal mucosae and in Caco-2 cell layers. Scand J Gastroenterol 47: 1321-1333, 2012.

2. Jovov B, Que J, Tobey NA, Djukic Z, Hogan BL and Orlando RC. Role of E-cadherin in the pathogenesis of gastroesophageal reflux disease. Am J Gastroenterol 106: 1039-1047, 2011.

3. Sherrill JD, Kc K, Wu D, Djukic Z, Caldwell JM, Stucke EM, Kemme KA, Costello MS, Mingler MK, Blanchard C, Collins MH, Abonia JP, Putnam PE, Dellon ES, Orlando RC, Hogan SP and Rothenberg ME. Desmoglein-1 regulates esophageal epithelial barrier function and immune responses in eosinophilic esophagitis. Mucosal Immunol 7: 718729, 2014.

4. Tobey NA, Argote CM, Vanegas XC, Barlow W and Orlando RC. Electrical parameters and ion species for active transport in human esophageal stratified squamous epithelium and Barrett's specialized columnar epithelium. Am J Physiol Gastrointest Liver Physiol 293: G264-G270, 2007.

5. Ungell AL, Nylander S, Bergstrand S, Sjoberg A and Lennernas $\mathbf{H}$. Membrane transport of drugs in different regions of the intestinal tract of the rat. J Pharm Sci 87: 360-366, 1998.

6. van Rhijn BD, Verheij J, van den Bergh Weerman MA, Verseijden C, van den Wijngaard RM, de Jonge WJ, Smout AJ and Bredenoord AJ. Histological Response to Fluticasone Propionate in Patients With Eosinophilic Esophagitis Is Associated With Improved Functional Esophageal Mucosal Integrity. Am J Gastroenterol 110: 1289-1297, 2015. 